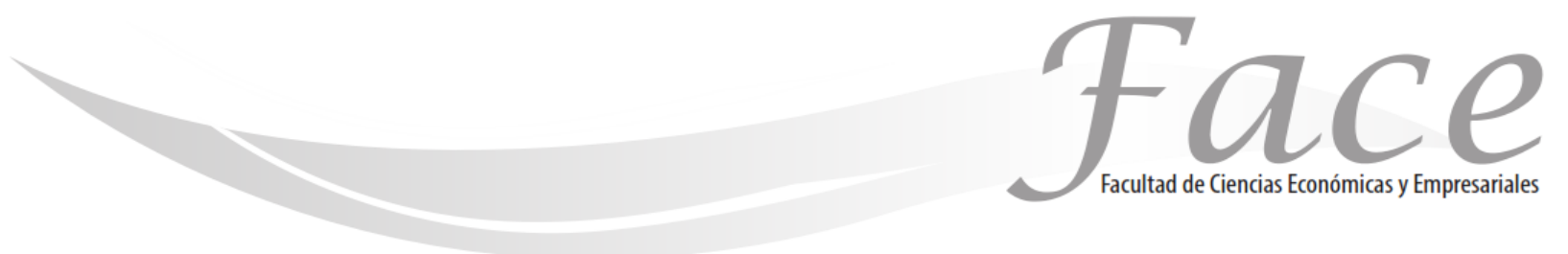

ISSN Impreso: 1794-9920

ISSN Electrónico: 2500-9338

Volumen $18-\mathrm{N}^{\circ} 1$

Año 2018

Págs. 53 - 75

\title{
SATISFACCIÓN DEL EMPLEADO COMO DETONANTE EN EL CLIMA LABORAL DE LAS UNIVERSIDADES PRIVADAS CON ENFOQUE RELIGIOSO: UN ANÁLISIS EN MÉXICO
}

\author{
Dr. Emigdio Larios Gómez * \\ Enlace ORCID: https://orcid.org/0000-0002-3514-1319
}

Fecha de Recepción: 30 de Abril 2018

Fecha de Aprobación: 24 de Julio 2018

\begin{abstract}
Resumen:
Se trata de una investigación de tipo concluyente-descriptiva, a través de la aplicación de una encuesta a directivos, coordinadores, docentes de tiempo completo, empleada y administrativa de las instituciones de educación superior con enfoque Religioso en Puebla, México. El objetivo fue analizar, evaluar y comparar el clima organizacional de tres universidades privadas en la Ciudad de Puebla con impacto nacional (con campus en otros estados del país) y con diferente enfoque o filosofía religiosa. Es decir, un análisis comparativo entre la universidad con enfoque católico (Jesuita), la universidad con enfoque evangélico-protestante (Metodista) y la universidad con enfoque laico (Empresarial). Se aplicó un instrumento de 50 ítems, a una muestra por conveniencia de 175 sujetos de forma personal y virtual (Skype, Google HangOut y Google Form). Asimismo, se realizó la prueba ANOVA para la comparación de medias de tres grupos clasificados como UM (universidad Metodista), UJ (universidad Jesuita) y UL (universidad Laica). Bajo un diseño ex post facto retrospectivo. Como principales hallazgos, encontramos que con base en la Correlación entre la Universidad Metodista con la Universidad Laica, se refuta la Hipótesis $\left(\mathrm{H}_{1}\right)$ La Satisfacción laboral (motivación) de los empleados en las universidades privadas con enfoque religioso influye en un mejor 0 un ambiente positivo en el clima laboral en comparación con las universidades con enfoque laico. Y respecto a la correlación entre la Universidad Jesuita con la Universidad Laica, se acepta la Hipótesis $\left(\mathrm{H}_{1}\right)$ La Satisfacción laboral (motivación) de los empleados en las universidades privadas con enfoque religioso influye en un mejor o un ambiente positivo en el clima laboral en comparación con las universidades con enfoque laico. Y con base en los resultados obtenidos en la comparación de medias (ANOVA), con una $p$ asociada de 0.004 , se rechaza la hipótesis nula $(\mathrm{Ho}): \mu 1=\mu 2=\mu 3$. Y se concluye que si hay diferencias entre el grado de satisfacción laboral por la influencia en este de la religión que profesan. Debido a que existe diferencia en todas las medias de los grupos $\mu 1$ (UM) $\mu 2$ (UJ) y $\mu 3$ (UL). 0 al menos en un grupo cuya media es distinta a la media del resto de los grupos. Debido al tipo de información proporcionada y a la solicitud de la mayoría de los participantes, se queda en anonimato el o los nombres de las universidades, para evitar el conflicto laboral de los entrevistados y su sentir real hacia la empresa. Además, de no hacer público el nombre de la empresa educativa porque la presente investigación solo tiene fines de investigación si fines de lucro y sin daño a terceros.
\end{abstract}

Palabras Clave: Educación Superior; Clima Laboral, Educación Religiosa, Motivación Laboral, Satisfacción Laboral; Universidades con enfoque Religioso

* Doctor en Ciencias Administrativas por el Instituto Politécnico Nacional (IPN). Profesor-Investigador en la Benemérita Universidad Autónoma de Puebla (BUAP). E-mail: herr.larios@gmail.com 


\section{SATISFACTION OF THE EMPLOYEE AS A DETONANTE IN THE LABOR CLIMATE OF PRIVATE UNIVERSITIES WITH A RELIGIOUS APPROACH: AN ANALYSIS IN MEXICO}

This is a conclusive-descriptive research, through the application of a survey of managers, coordinators, full-time teachers, employed and administrative institutions of higher education with a religious approach in Puebla, Mexico. The objective was to analyze, evaluate and compare the organizational climate of three private universities in the City of Puebla with national impact (with campuses in other states of the country) and with a different religious philosophy or approach. That is to say, a comparative analysis between the university with a Catholic approach (Jesuit), the university with Evangelical-Protestant approach (Methodist) and the university with a secular (Business) approach. A 50-item instrument was applied to a convenience sample of 175 subjects on a personal and virtual basis (Skype, Google HangOut and Google Form). Likewise, ANOVA was used to compare means of three groups classified as UM (Methodist University), UJ (Jesuit University) and UL (Laica University). Under an ex post facto retrospective design. As main findings, we find that based on the correlation between the Methodist University and Laica University, the Hypothesis (H1) is refuted. Job satisfaction (motivation) of employees in private universities with a religious focus influences a better or an environment positive in the work climate compared to secular universities. And with respect to the correlation between the Jesuit University and the Laic University, the Hypothesis (H1) is accepted. Work satisfaction (motivation) of employees in private universities with a religious focus influences a better or a positive environment in the workplace environment in comparison with secular universities. And based on the results obtained in the comparison of means (ANOVA), with an associated $p$ of 0.004 , the null hypothesis $(\mathrm{Ho}): \mu 1=\mu 2=\mu 3$ is rejected. And it is concluded that if there are differences between the degree of job satisfaction by the influence in this of the religion they profess. Because there is difference in all means of the groups $\mu 1(\mathrm{UM}) \mu 2(\mathrm{UJ})$ and $\mu 3(\mathrm{UL})$. Or at least in a group whose mean is different from the average of the rest of the groups. Due to the type of information provided and the request of the majority of the participants, the names or names of the universities remain anonymous, in order to avoid the labor conflict of the interviewees and their real feelings towards the company. Also, not to make public the name of the educational company because the present investigation is for research purposes only for profit and without harm to third parties.

Palabras Clave: Higher education; Labor Climate, Religious Education, Work Motivation, Labor Satisfaction; Universities with a Religious focus. 


\section{SATISFAÇÃO DO EMPREGADO COMO DETONANTE NO CLIMA LABORAL DAS UNIVERSIDADES PRIVADAS COM UMA ABORDAGEM RELIGIOSA: UMA ANÁLISE NO MÉXICO}

Esta é uma investigação conclusiva-descritiva, através da implementação de uma pesquisa com gerentes, coordenadores, professores inteiro, tempo empregado e instituições administrativas de ensino superior com a abordagem religiosa em Puebla, México. $O$ objetivo foi analisar, avaliar e comparar o clima organizacional de três universidades privadas na cidade de Puebla com impacto nacional (com campi em outros estados) e uma abordagem diferente ou filosofia religiosa. Isto é, uma análise comparativa entre a universidade com um foco católico (jesuíta), a universidade com um foco evangélico-protestante (metodista) e uma universidade com um foco leigo (negócios). Um instrumento de 50 itens foi aplicado a uma amostra de conveniência de 175 sujeitos de maneira pessoal e virtual (Skype, Google HangOut e Google Form). Da mesma forma, o teste ANOVA foi realizado para comparar as médias de três grupos classificados como UM (Universidade Metodista), UJ (Universidade Jesuíta) e UL (Universidade Lay). Sob uma retrospectiva ex post facto design. Principais conclusões, nós achamos que com base na correlação entre a Universidade Metodista com a Universidade Hipótese Secular (H1) refuta a satisfação no trabalho (motivação) dos empregados em universidades privadas com religiosos abordagem influencia melhor ou atmosfera positivo no clima de trabalho em comparação com as universidades com uma abordagem secular. E quanto à correlação entre a Universidade jesuíta com a Universidade de Lay, a hipótese (H1) é a satisfação no trabalho aceito (motivação) dos empregados em universidades privadas com abordagem religiosa influencia melhor ou uma atmosfera positiva no ambiente de trabalho em Comparação com universidades com uma abordagem secular. $\mathrm{E}$ com base nos resultados obtidos na comparação de médias (ANOVA), com um $p$ associado de 0,004, a hipótese nula $(\mathrm{Ho})$ é rejeitada: $\mu 1=\mu 2=\mu 3$. E conclui-se que existem diferenças entre 0 grau de satisfação no trabalho devido à influência desta religião que professam. Porque há uma diferença em todas as médias dos grupos $\mu 1$ (UM) $\mu 2$ (UJ) e $\mu 3$ (UL). Ou pelo menos em um grupo cuja média é diferente da média do resto dos grupos. Devido ao tipo de informação fornecida e a solicitação da maioria dos participantes, os nomes das universidades permanecem anônimos, para evitar o conflito de trabalho dos entrevistados e seu real sentimento em relação à empresa. Além disso, não tornar público 0 nome da empresa educacional, pois a presente investigação tem apenas fins de pesquisa com fins lucrativos e sem prejuízo para terceiros.

Palavras chave: Educação superior; Clima Trabalhista, Educação Religiosa, Motivação no Trabalho, Satisfação no Trabalho; Universidades com foco religioso 


\section{INTRODUCCIÓN:}

La educación superior privada en México, como en América Latina, surge prácticamente con la creación de las universidades desde el siglo XVII, administradas por diversas órdenes religiosas como la Compañía de Jesús, quien en el año 1640 contaba con 500 centros de estudios superiores repartidos por Europa y América como parte de la evangelización católica en el mundo. Posteriormente, con la expulsión de la Compañía de Jesús de España y concretamente de todos los territorios de la Corona Española en 1767 y de Portugal en 1759, se da paso al proceso de expansión de la educación superior pública y laica (Rama, 2012).

A partir de las independencias en los países latinoamericanos desde 1809 y de las reformas educativas en los últimos 200 años, se han incrementado la privatización de escuelas y universidades, y nuevamente han facilitado la penetración de congregaciones religiosas diversas, así como alternativas laicas en el campo educativo. El incremento en el número de instituciones de educación superior ha sido acelerado en todo el mundo (incluyendo México), proliferando diversas orientaciones, es decir, a la par de universidades tradicionales de investigación han surgido instituciones de corte técnico, politécnico, escuelas profesionales, establecimientos que ofrecen licenciaturas y posgrados (pero no realizan investigación), así como centros de educación popular y todas ellas con características tanto de orden público como privado (Muñoz-Sedano, 1992), con enfoques lucrativos, no lucrativos, organizaciones filantrópicas, de orden corporativo y religiosas (Banco Mundial, 2000). Y todas ellas coincidiendo tanto en objetivos educativos, comerciales y la creación de conocimiento.

La mejora en las tasas de matriculación en los niveles educativos y las mencionadas reformas educativas tienden a impactar la cultura, modificando la mentalidad de las nuevas generaciones, haciéndolas más abiertas al cambio y a la diversidad, todo lo cual legitima las diferentes opciones en el campo espiritual y religioso. Rodríguez (1999), afirma que para empezar a hablar de la Educación Superior en México, es necesario recordar los acontecimientos históricos en los cuales han interactuado múltiples factores y diversos actores: 1). Las relaciones entre el Estado y el sistema de enseñanza superior en general, 2). La configuración de demandas sociales sobre la universidad, 3). La movilización de los actores universitarios -es decir, de los académicos, estudiantes y trabajadores- dentro de las instituciones y 4).
La adaptación de modelos internacionales de desarrollo de la enseñanza superior. Teniendo que en las tres últimas décadas del siglo XX se han presentado tres etapas 0 fases de desarrollo en la educación superior del país:

Expansión, Desaceleración y Evaluación (Topete \& Cerecedo, 2001).

\section{MARCO REFERENCIAL:}

\section{RELIGIÓN Y EDUCACIÓN}

La religión es inherente al hombre, es un hecho humano complejo y específico; un conjunto de creencias, de prácticas, de símbolos, de estructuras sociales, a través de las cuales el hombre en las diferentes culturas y épocas vive su relación con el mundo sagrado (Cáceres, 2010). América Latina está siendo transformada bajo diversos aspectos y el cambio religioso experimentado en los últimos treinta años nos está ofreciendo un panorama cultural y social muy característico en la primera década de este siglo. Al respecto, Velasco (2004) considera a la religión como un hecho humano complejo y específico; un conjunto de creencias, de prácticas, de símbolos, de estructuras sociales, a través de las cuales el hombre en las diferentes culturas y épocas, vive su relación con el mundo sagrado. Este hecho se caracteriza por su complejidad, debido a que en él se ponen en juego todos los niveles de la conciencia humana y por la intervención en él de una intención específica de referencia, a una realidad superior, invisible, trascendente, misteriosa de la que se hace depender el sentido último de la vida.

Por consiguiente, la religión cristiana -tanto Católica como Evangélica/Protestante- representa una visión global de la vida y su valor reside en que corresponde a un tipo de sensibilidad humana, a la de una comunidad de creyentes o más extensible a una sociedad en pleno, que encuentran en sus sistemas simbólicos sacralizados, en su moral decalogicista (centrada en los diez mandamientos) y en sus rituales sacrosantos, una correspondencia a sus necesidades de significado. De ahí que no sólo el temor ante lo sagrado, sino también la esperanza de un mundo mejor ajeno a las decadentes vías del absolutismo profano, sean algo esencial a toda la cristiandad y a toda espiritualidad verdadera. Cuanto mayor es la sensibilidad religiosa de un creyente, tanto más se percibe y 
comprende la relacionalidad entre la voluntad humana y los designios Divinos (Mass \& Edelberg, 2006).

Desde la perspectiva religiosa, el papel de la educación y los cambios de mentalidad de la sociedad deben ser considerados como principales en el proceso que conduce hacia el pluralismo religioso creciente. La educación moderna permite que el sujeto entre en contacto con un horizonte cultural más amplio, con estilos de vida diversos, e introduce en él una apreciación crítica de las cosas que tiende a cuestionar la tradición moral y los dogmas. Indagar en los orígenes de lo religioso en la Educación se torna difícil, pero podemos decir que desde el principio de los tiempos el ser humano ha vivido dependiendo y sujeto a las fuerzas de la naturaleza, muchas veces sin explicación del porqué de las cosas; lo desconocido ha provocado temor $y$ eso ha generado la búsqueda de una idea explicativa, un ente que ordene el mundo, un todopoderoso.

Los referentes históricos de la religiosidad en México atraviesan por los conceptos de conflictos religiosos y convivencia interreligiosa. Existen diversos casos dónde la pertenencia religiosa es el punto nodal de conflictos. Asumir la propia religiosidad ha influido en algunos grupos religiosos a diferenciarse de los demás, genera un conflicto ante la convivencia con creencias diferentes; y en ocasiones, la solución al mismo es la agresión o la expulsión, real o simbólica.

Un estudio de la religiosidad debería de considerar el conflicto y la convivencia como elemento constitutivo de la estructura del pensamiento religioso. De igual forma, la preferencia religiosa presenta una fuerte asociación con la preferencia política. Rokeach (1960 y 1973) ha señalado el constructor de sistema de creencias, como una estructura sociocognoscitiva que se genera en los grupos sociales e individuos para explicarse el entorno social.

Las preferencias políticas de tendencia "derecha», estructuran su discurso y documentos en torno a elementos de «moral», "valores» y "ser humano» los cuales tienen similitud con los elementos que favorece el discurso religioso, específicamente, la iglesia católica (Alford, 1980; Blanco, 2003; De la Rosa, 1985; Luengo, 1993). Se considera que los jóvenes universitarios son el escenario adecuado, dado que aún conservan los elementos de religiosidad que en sus familias se inculquen como aquellas que se compartan con sus compañeros universitarios; además, de que están en una etapa dónde buscan consolidar o cambiar sus propias creencias, conformando su identidad.
Para Cáceres (2010), el Cristianismo Católico y Protestante es trascendente en la formación profesional del universitario, porque le ayuda a estar orientado en su proceso de adquisición de nuevos conocimientos de forma integral guiado por su Fe. Mientras que los universitarios no creyentes optan por emprender acciones hedonistas, placer sexual y consumo etílico.

Además agrega, que el proceso de testificación del creyente cristiano en el contexto universitario, se hace notorio no solo en el estudiante, sino también en el personal docente y demás autoridades universitarias, reflejándose en los idearios universitarios tanto del Cristianismo Católico y del Protestante, la existencia de un sistema de vida existencial gratificante, al poseer un enfoque religioso.

\section{EL CLIMA LABORAL EN LAS ORGANIZACIONES}

En la actualidad pocas organizaciones se dan a la tarea de estudiar y analizar el clima laboral que hay entre los empleados, además de conocer lo que los empleados piensan de la empresa. Sin embargo el correcto análisis de la percepción de los trabajadores con respecto a las condiciones laborales, ergonómicas, ambientales, económicas, de seguridad y ascenso laboral son de vital interés, puesto de dicho análisis se pueden obtener grandes ideas y lograr mejoras para potencializar el capital intelectual con el que ya se cuenta. En algunas empresas, muchas veces se aplican las estrategias "tradicionales" para motivar al personal, en esta visión antigua se tiene como principal aspecto el que la gente se mueve por miedo, no quieren perder su trabajo y por lo tanto hacen lo que les corresponde, sin embargo hay que buscar la mejor manera de obtener todo el rendimiento posible de los empleados y no basta con atemorizarlos para obtener productividad, puesto que la creatividad e innovación, creo, no se da en ambientes hostiles en donde no hay cabida a la libertad. 
ISSN: 1794-9920 - ISSN Electrónico: 2500-9338

Enero - Julio de 2018

Volumen 18 Número 1, Año 2018 Págs. 53 - 75
Las organizaciones, sin importar el tipo de estas, se encuentran formadas por personas y las relaciones interpersonales se dan con el fin de desempeñar acciones que ayuden al logro de las metas. Tratar de entender el impacto que los individuos, los grupos y la estructura tienen sobre el comportamiento dentro de la organización, permite mejorar la eficacia de ésta y el alcance de sus objetivos, este comportamiento se da debido a la cultura organizacional que en ellas prevalece (Zamora, 2005).

Reflejo de ello es el clima organizacional, por lo que para conocer las percepciones que el trabajador tiene de las características de la organización, que influyen en las actitudes y comportamiento de los empleados, es necesario elaborar diagnósticos de clima organizacional (CO). El desarrollo organizacional surge en 1962 introducido por primera vez al área de psicología organizacional por Gellerman, como un conjunto de ideas sobre el hombre, la organización y el ambiente, con el propósito de facilitar el crecimiento y desarrollo de las organizaciones.

El clima organizacional está relacionado con el surgimiento del desarrollo organizacional y de la aplicación de la teoría de sistemas al estudio de las organizaciones. Y la relación sistema-ambiente proveniente de la Teoría General de Sistemas, propuesta por Von Bertalanffy.

Los sistemas organizacionales están en relación con su entorno ambiental de la Escuela Clásica que tienen su origen en la Escuela de Relaciones Humanas (Rodríguez, 1999). El clima organizacional, también conocido como clima laboral, ambiente laboral o ambiente organizacional, $y$ es un asunto de importancia para aquellas organizaciones competitivas que buscan lograr una mayor productividad y mejora en el servicio ofrecido, por medio de estrategias internas. El clima organizacional, debe de concebirse como un conjunto de propiedades medibles del ambiente de trabajo que son percibidos por los empleados, directivos y personal de apoyo que integran la empresa y que trabajan en ella.

Este ambiente influencia su motivación y comportamiento (Ahmed, Khan, \& Butt, 2012). Generando variables que se relacionan con el bienestar de los trabajadores en su trabajo, en sus relaciones con sus superiores, iguales y subordinados, afectan o benefician su calidad de vida laboral repercutiendo en su desempeño (Peña, Díaz, \& Carrillo, 2013).
Existen infinidad de autores, investigadores y especialistas que han analizado, estudiado y practicado el clima organizacional 0 laboral desde muchos ángulos y perspectivas. Desde la visión de la satisfacción aboral, desde una perspectiva conceptual, desde la psicología laboral y muchas más orientaciones. Pero existen muy pocas investigaciones que relacionen el estudio del clima laboral con el enfoque religioso existente en las empresas y en este caso la empresa educativa. Para el análisis del clima laboral de las instituciones de educación superior en la presente investigación, en la Tabla 1, se han resumido las diferentes aportaciones de los autores más representativos respecto al clima laboral. Ver tabla 1.

Brunet, (2004), la cual señala que la teoría del clima organizacional, o de los sistemas de organización, de Rensis Likert, permite visualizar en términos de causa y efecto la naturaleza de los climas que se estudian, y permite también analizar el papel de las variables que conforman el clima que se observa.

En la teoría de Sistemas, Likert, (citado por Brunet, 2004) plantea que el comportamiento de los subordinados es causado, en parte, por el comportamiento administrativo y por las condiciones organizacionales que éstos perciben $y$, en parte, por sus informaciones, sus percepciones, sus esperanzas, sus capacidades y sus valores. Esto, relacionado con el enfoque de la filosofía institucional de la organización, para el caso de los sujetos de estudio del presente, se relaciona con el enfoque religioso de las universidades. 

ANÁLISIS EN MÉXICO

Emigdio Larios Gómez

Tabla 1.

Revisión de la Literatura: Clima Laboral.

\begin{tabular}{|c|c|}
\hline Autor & ión \\
\hline Brunet (1987) & $\begin{array}{l}\text { Para definir al clima laboral, se debe pensar en dos grandes escuelas de pensamiento: la escuela de Gestalt, } \\
\text { donde los individuos comprenden el mundo que les rodea basados en criterios percibidos e inferidos, de tal } \\
\text { manera que se comportan en función de la forma en que perciben su mundo. Es así que el comportamiento de } \\
\text { un empleado está influenciado por la percepción que él mismo tiene sobre el medio de trabajo y del entorno. Y } \\
\text { la escuela funcionalista, dice que el pensamiento y comportamiento de un individuo dependen del ambiente que } \\
\text { le rodea y que las diferencias individuales juegan un papel importante en la adaptación del individuo a su medio. }\end{array}$ \\
\hline $\begin{array}{l}\text { Rodríguez } \\
\text { (1999) }\end{array}$ & $\begin{array}{l}\text { El clima laboral es el conjunto de actitudes y ambiente que se desarrolla en las relaciones humanas del } \\
\text { personal, con el que cuenta una organización, asimismo es la manera en cómo se trabaja en ella, puesto que se } \\
\text { tienen hábitos entre el personal que nos dan idea de cómo es la cultura empresarial de una entidad. Y la } \\
\text { importancia de esto, radica en los resultados cualitativos y cuantitativos producto de directivos, empleados y } \\
\text { personal en general, si una organización presenta problemas en el clima laboral se tendrá repercusiones } \\
\text { negativas en dichos resultados. Rodríguez, (1999) expresa que el clima organizacional se refiere a las } \\
\text { percepciones compartidas por los miembros de una organización respecto al trabajo, el ambiente físico en que } \\
\text { éste se da, las relaciones interpersonales que tienen lugar en torno a él y las diversas regulaciones formales } \\
\text { que afectan dicho trabajo. }\end{array}$ \\
\hline Anzola (2003) & $\begin{array}{l}\text { El clima se refiere a las percepciones e interpretaciones relativamente permanentes que los individuos tienen } \\
\text { con respecto a su organización, que a su vez influyen en la conducta de los trabajadores, diferenciando una } \\
\text { organización de otra. }\end{array}$ \\
\hline $\begin{array}{l}\text { Seisdedos } \\
\text { (1996) }\end{array}$ & $\begin{array}{l}\text { Denomina al clima organizacional como conjunto de percepciones globales que el individuo tiene de la } \\
\text { organización, reflejo de la interacción entre ambos. Dice que lo importante es cómo percibe el sujeto su entorno, } \\
\text { independientemente de cómo lo perciben otros, por lo tanto es más una dimensión del individuo que de la } \\
\text { organización. }\end{array}$ \\
\hline Schein citado & Menciona que el ambiente organizacional, a veces llamada atmósfera o cultura organizacional, es el conjunto de \\
\hline $\begin{array}{l}\text { por } \\
\text { (1991) }\end{array}$ & suposiciones, creencias, valores y normas que comparten sus miembros. \\
\hline Dessler (1979) & $\begin{array}{l}\text { Plantea que no hay un consenso en cuanto al significado del término de clima organizacional, las definiciones } \\
\text { giran alrededor de factores organizacionales puramente objetivos como estructura, políticas y reglas, hasta } \\
\text { atributos percibidos tan subjetivos como la cordialidad y el apoyo. }\end{array}$ \\
\hline $\begin{array}{l}\text { Méndez- } \\
\text { Álvarez (2006) }\end{array}$ & $\begin{array}{l}\text { Refiere al clima organizacional como el ambiente propio de la organización, producido y percibido por el } \\
\text { individuo de acuerdo a las condiciones que encuentra en su proceso de interacción social y en la estructura } \\
\text { organizacional que se expresa por variables (objetivos, motivación, liderazgo, control, toma de decisiones, } \\
\text { relaciones interpersonales y cooperación) que orientan su creencia, percepción, grado de participación y actitud; } \\
\text { determinando su comportamiento, satisfacción y nivel de eficiencia en el trabajo. }\end{array}$ \\
\hline $\begin{array}{l}\text { Chiavenato } \\
\text { (2001) }\end{array}$ & $\begin{array}{l}\text { La cultura organizacional se manifiesta a través del comportamiento y el clima organizacional. Si bien, en todo } \\
\text { este proceso de cambio, en atención a las exigencias del exterior, las organizaciones también deben } \\
\text { preocuparse por todo aquello que ocurre dentro de la organización, es decir el clima organizacional (CO), el cual } \\
\text { se entiende como el conjunto de percepciones de las características relativamente estables de la organización, } \\
\text { que influyen en las actitudes y el comportamiento de sus miembros. }\end{array}$ \\
\hline $\begin{array}{l}\text { Ahmed, Khan, } \\
\text { \& Butt (2012) }\end{array}$ & $\begin{array}{l}\text { El clima organizacional se define como un conjunto de propiedades medibles del ambiente de trabajo que son } \\
\text { percibidos por las personas, influenciando su ambiente, su motivación y su comportamiento. }\end{array}$ \\
\hline $\begin{array}{l}\text { Peña, Díaz, \& } \\
\text { Carrillo (2013). }\end{array}$ & $\begin{array}{l}\text { El clima laboral, se relaciona con el bienestar de los trabajadores en su trabajo, en sus relaciones con las } \\
\text { personas que afectan o benefician su calidad de vida laboral repercutiendo en su desempeño. }\end{array}$ \\
\hline $\begin{array}{l}\text { Cuadra y } \\
\text { Veloso (2007) }\end{array}$ & $\begin{array}{l}\text { En el seguimiento y la evaluación del clima organizacional, el alto porcentaje de incremento en variables } \\
\text { consideradas positivas en cuanto al clima laboral: satisfacción laboral, disminución de la tensión e incremento } \\
\text { del liderazgo, provoca una baja de accidentes, de días no trabajados y aumento de la productividad. }\end{array}$ \\
\hline Ramihic (2013) & $\begin{array}{l}\text { El clima organizacional influye significativamente sobre la satisfacción laboral, es decir, los cambios en la } \\
\text { satisfacción laboral son influenciados por cambios en el clima organizacional. }\end{array}$ \\
\hline Zamora (2005) & $\begin{array}{l}\text { El Clima puede construirse como una autoreflexión de los miembros de la organización acerca de su vinculación } \\
\text { entre sí y con el sistema organizacional. }\end{array}$ \\
\hline $\begin{array}{l}\text { Goncalves } \\
\text { (1997) citado } \\
\text { por Cárdenas, } \\
\text { Arciniegas, \& } \\
\text { Barrera (2011) }\end{array}$ & $\begin{array}{l}\text { Se define el clima organizacional como un fenómeno que media entre los factores del sistema organizacional y } \\
\text { las tendencias motivacionales que se traducen en un comportamiento que tiene consecuencias sobre la } \\
\text { organización, tales como la productividad, satisfacción, rotación, etc. Además, el clima organizacional puede } \\
\text { medirse con una diversidad de indicadores objetivos y subjetivos. }\end{array}$ \\
\hline
\end{tabular}
Barrera (2011)

Fuente: Elaboración propia con información de Brunet, (1987), Rodríguez (1999), Anzola (2003), Seisdedos (1996), Schein, (citado por Davis, 1991), Dessler (1979), Méndez-Álvarez (2006), Chiavenato (2001), Hall, (citado por Álvarez, 2007), Ahmed, Khan, \& Butt (2012). Peña, Díaz, \& Carrillo (2013), Cuadra y Veloso (2007), Ramihic (2013), Zamora (2005), Goncalves (1997) citado por Cárdenas y Arciniegas, \& Barrera (2011). 
ISSN: 1794-9920 - ISSN Electrónico: 2500-9338

Enero - Julio de 2018

Volumen 18 Número 1, Año 2018 Págs. 53 - 75

nrotestante es trascendente en la formación

Likert, (citado por Brunet, 1987) en su teoría de los sistemas, determina cuatro grandes tipos de clima organizacional, o de sistemas. Menciona Brunet que se debe evitar confundir la teoría de los sistemas de Likert con las teorías de liderazgo, pues el liderazgo constituye una de las variables explicativas del clima y el fin que persigue la teoría de los sistemas es presentar un marco de referencia que permita examinar la naturaleza del clima y su papel en la eficacia organizacional. Y se describen en la Tabla 2:

Tabla 2.

Tipos de clima organizacional de Brunet.

\begin{tabular}{|c|c|}
\hline $\begin{array}{l}\text { Tipos de Clima } \\
\text { Laboral }\end{array}$ & Descripción \\
\hline $\begin{array}{l}\text { Clima de tipo } \\
\text { autoritario: Sistema } \\
\text { I Autoritarismo } \\
\text { explotador }\end{array}$ & $\begin{array}{l}\text { En este tipo de clima la dirección no tiene confianza en sus empleados. La mayor parte delas decisiones y } \\
\text { de los objetivos se toman en la cima de la organización y se distribuyen según una función puramente } \\
\text { descendente. Los empleados tienen que trabajar dentro de una atmosfera de miedo, de castigos, de } \\
\text { amenazas, ocasionalmente de recompensas, y la satisfacción de las necesidades permanece en los niveles } \\
\text { psicológicos y de seguridad. Este tipo de clima presenta un ambiente estable y aleatorio en el que la } \\
\text { comunicación de la dirección con sus empleados no existe más que en forma de directrices y de } \\
\text { instrucciones específicas. }\end{array}$ \\
\hline $\begin{array}{l}\text { Clima de tipo } \\
\text { autoritario: Sistema } \\
\text { II - Autoritarismo } \\
\text { paternalista }\end{array}$ & $\begin{array}{l}\text { Este tipo de clima es aquel en el que la dirección tiene una confianza condescendiente en sus empleados, } \\
\text { como la de un amo con su siervo. La mayor parte de las decisiones se toman en la cima, pero algunas se } \\
\text { toman en los escalones inferiores. Las recompensas y algunas veces los castigos son los métodos } \\
\text { utilizados por excelencia para motivar a los trabajadores. Bajo este tipo de clima, la dirección juega mucho } \\
\text { con las necesidades sociales de sus empleados que tienen, sin embargo, la impresión de trabajar dentro de } \\
\text { un ambiente estable y estructurado. }\end{array}$ \\
\hline $\begin{array}{ll}\text { Clima de } & \text { tipo } \\
\text { participativo: } & \\
\text { Sistema III } & - \\
\text { Consultivo } & \end{array}$ & $\begin{array}{l}\text { La dirección que evoluciona dentro de un clima participativo tiene confianza en sus empleados. La política y } \\
\text { las decisiones de toman generalmente en la cima pero se permite a los subordinados que tomen decisiones } \\
\text { más específicas en los niveles inferiores. La comunicación es de tipo descendente. Las recompensas, los } \\
\text { castigos ocasionales y cualquier implicación se utilizan para motivar a los trabajadores; se trata también de } \\
\text { satisfacer sus necesidades de prestigio y de estima. Este tipo de clima presenta un ambiente bastante } \\
\text { dinámico en el que la administración se da bajo la forma de objetivos por alcanzar. }\end{array}$ \\
\hline $\begin{array}{l}\text { Clima de tipo } \\
\text { participativo: } \\
\text { Sistema IV } \\
\text { Participación en } \\
\text { grupo }\end{array}$ & $\begin{array}{l}\text { La dirección tiene plena confianza en sus empleados. Los procesos de toma de decisiones están } \\
\text { diseminados en toda la organización y muy bien integrados a cada uno de los niveles. La comunicación no } \\
\text { se hace solamente de manera ascendente o descendente, sino también de forma lateral. Los empleados } \\
\text { están motivados por la participación y la implicación, por el establecimiento de objetivos de rendimiento, por } \\
\text { el mejoramiento de los métodos de trabajo y por la evaluación del rendimiento en función de los objetivos. } \\
\text { Existe una relación de amistad y confianza entre los superiores y subordinados. En resumen, todos los } \\
\text { empleados y todo el personal de dirección forman un equipo para alcanzar los fines y los objetivos de la } \\
\text { organización que se establecen bajo la forma de planeación estratégica. }\end{array}$ \\
\hline
\end{tabular}

Fuente: Elaboración propia con información de Likert citado por Brunet (1987).

Con base en las definiciones mencionadas, podemos definir al clima laboral como las percepciones compartidas que tienen los miembros de una organización (empleados, directivos, personal de apoyo y socios) acerca de los procesos organizacionales, tales como las políticas, el estilo de liderazgo, las relaciones interpersonales, la remuneración, etc., y su repercusión o influencia ya sea positiva o negativa en la satisfacción laboral, el ambiente de trabajo y por ende en la productividad de la empresa. Es importante recordar que la percepción de cada integrante de la empresa es distinta y ésta determina su comportamiento en la organización por lo que el clima organizacional varía de una organización a otra. Más aún, si se tratase de empresas con un enfoque religioso, de acuerdo con Cáceres (2010), el Cristianismo católico y

Desde el directivo principal (Rector), de los directivos (áreas sustantivas de la universidad o escuela) y en desde los docentes quienes tienen el contacto directo con el cliente-alumno. Lo que se pretende en esta investigación, es analizar y comparar el clima laboral de universidades privadas con enfoque religioso y no religioso (laica), que permita determinar el tipo de clima laboral que prevalece. Para lo cual se plantea la siguiente pregunta ¿EI clima laboral en empresas educativas con enfoque religioso es más positivo al clima laboral en empresas educativas sin enfoque religioso? ¿Una filosofía religiosa tiene influencia sobre el ambiente o clima laboral de la empresa educativa?. 


\section{METODOLOGÍA:}

El presente trabajo de investigación ${ }^{1}$, sólo contempla el tipo concluyente-descriptiva (Kerlinger, 2002), a través de la aplicación de una encuesta a directivos, coordinadores, docentes de tiempo completo, empleados y administrativos de las instituciones de educación superior participantes. El objetivo fue analizar, evaluar y comparar el clima organizacional de tres universidades privadas en la Ciudad de Puebla con impacto nacional (con campus en otros estados del país) y con diferente enfoque o filosofía religiosa. Es decir, un análisis comparativo entre la universidad con enfoque católico (Jesuita), la universidad con enfoque evangélico-protestante (Metodista) y la universidad con enfoque laico (Empresarial). Se diseñó y aplicó el instrumento de 50 ítems, elaborado con base en la propuesta de García e Ibarra (2010) en su trabajo sobre el diagnóstico del clima laboral del departamento de Educación de la Universidad de Guanajuato en México, redactando los ítems en forma descriptiva, como se puede observar en la Tabla 3 de operacionalización de variables. Se aplicó la investigación a una muestra por conveniencia de 175 sujetos (encuesta) ${ }^{2}$, quienes desempeñan funciones como coordinadores de carrera, coordinadores administrativos y directivos de área, así como administrativos, empleados y docentes. Para todos los casos el método fue de forma personal y virtual (Skype, Google HangOut y Google Form). Debido al tipo de información proporcionada y a la solicitud de la mayoría de los participantes, se queda en anonimato el o los nombres de las universidades, para evitar el conflicto laboral de los entrevistados y su sentir real hacia la empresa. Además, de no hacer público el nombre de la empresa educativa porque la presente investigación solo tiene fines de investigación si fines de lucro y sin daño a terceros.

\footnotetext{
1 La investigación presentada solo es una parte de ella, ya que se describen los resultados cuantitativos o concluyentes. Debido a que originalmente se realizó una investigación de tipo Mixta CUAN y CUAL, con un diseño concurrente. Los resultados cualitativos no se presentan.

2 Para la etapa exploratoria, se entrevistaron a 25 sujetos: en la Universidad Jesuita se entrevistaron a 9 sujetos, para la Universidad Metodista a 7 sujetos y para la Universidad Laica-Empresarial a 9 sujetos.
}

Operacionalización de variables. La propuesta de García e Ibarra (2010), define a las dimensiones del clima organizacional, como aquellas características que influyen en el comportamiento de los individuos y que pueden ser medidas. $Y$ están integradas por los siguientes fundamentos teóricos:

- Likert, (citado por Brunet, 2004) mide la percepción del clima en función de ocho dimensiones: 1. Los métodos de mando, 2. Las características de las fuerzas motivacionales, 3. Las características de los procesos de comunicación, 4. Las características de los procesos de influencia, 5. Las características de los procesos de toma de decisiones, 6. Las características de los procesos de planeación, 7. Las características de los procesos de control y 8. Los objetivos de rendimiento y de perfeccionamiento.

- Brunet, (1987) menciona 11 dimensiones basados en Pritchard y Karasick: 1. Autonomía, 2. Conflicto y cooperación, 3. Relaciones Sociales, 4. Estructura, 5. Remuneración, 6. Rendimiento. (remuneración), 7. Motivación, 8. Estatus, 9. Flexibilidad e innovación, 10. Centralización de la toma de decisiones y 11. Apoyo.

- Rodríguez (1999) menciona seis dimensiones basado en Litwin y Stringer: 1. Estructura organizacional, 2. Remuneraciones, 3. Responsabilidad, 4. Riesgos y toma de decisiones, 5. Apoyo y 6. Conflicto.

- Campbell, (citado por Silva, 1996) estima las siguientes dimensiones: 1. Autonomía individual, 2. Grado de estructura del puesto, 3. Recompensa y 4. Consideración, agradecimiento y apoyo.

Es así, como se observa en la Tabla 3, que las diez dimensiones del modelo de García e Ibarra (2010) son: 1. Remuneración, 2. Relaciones personales, 3. Conflicto, 4. Compromiso organizacional, 5. Motivación, 6. Autonomía, 7. Formación profesional, 8. Liderazgo, 9. Planeación y 10. Comunicación:

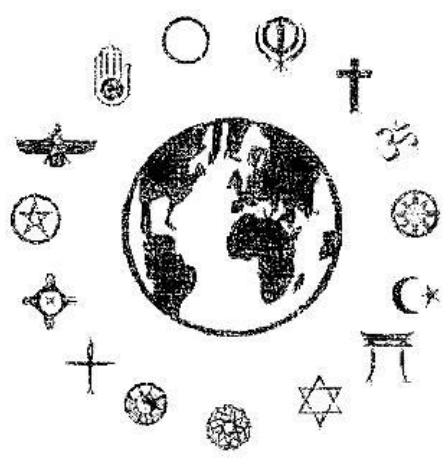


Tabla 3.

Dimensiones del Clima Laboral.

Dimensión

1. Remuneración:

2. Relaciones personales:

3. Conflicto:

4. Compromiso organizacional:

5. Motivación:

6. Autonomía:

7. Formación profesional:

8. Liderazgo:

9. Planeación:

10.

Comunicación:

\section{Descripción}

Grado de satisfacción en relación al pago y prestaciones que recibe el empleado a cambio de su trabajo.

Grado de respeto, apoyo y consideración entre los compañeros del Departamento.

Grado en que las diferencias personales pueden interferir en el buen desempeño de los empleados.

Grado en que los trabajadores se sienten comprometidos con el Departamento, con sus metas y objetivos de manera que puedan brindar un servicio de calidad.

Grado en que el empleado siente satisfacción en el puesto y las actividades que realiza.

Grado en que el trabajador es capaz de tomar decisiones y es responsable de las actividades que realiza.

Grado en el empleado se encuentra satisfecho con las actividades que el Departamento le brinda en beneficio de su crecimiento y desarrollo profesional.

Grado en que los jefes apoyan, estimulan y dan participación a sus colaboradores.

Nivel de efectividad en el establecimiento de objetivos, distribución de actividades y responsabilidades.

Nivel de efectividad en el flujo de información para la adecuada consecución de tareas.
Ítem / Indicador

3 Satisfacción de necesidades

14 Remuneración justa

37 Remuneración en relación al esfuerzo

50 Remuneración en relación a las horas trabajadas

4 Apoyo entre compañeros de trabajo

13 Relación con el jefe

27 Relación profesional con compañeros de trabajo

34 Relación informal con compañeros de trabajo

45 Igualdad de trato

5 Apoyo en la solución de problemas

12 Dificultad para trabajar con compañeros

23 Solución de problemas

39 Conflicto interpersonal

47 Obstaculización del trabajo

6 Compromiso laboral

11 Orgullo del centro de trabajo

28 Compromiso a trabajar con calidad

33 Recomendación del centro de trabajo

40 Sentimiento de brindar servicios de calidad

9 Interés en el puesto de trabajo

25 Reconocimiento

30 Interés en las actividades laborales

42 Realización personal

2 Sentimiento de autoridad

26 Iniciativa

35 Autonomía laboral

46 Libertad en toma de decisiones

10 Igualdad de oportunidades

20 Desarrollo profesional

31 Participación en actividades en pro del crecimiento profesional

41 Actividades laborales y desarrollo profesional

48 Crecimiento profesional

7 Liderazgo orientado al logro

17 Liderazgo Participativo

24 Liderazgo apoyador

38 Liderazgo directivo

43 Existencia de liderazgo

1 Políticas de trabajo

16 Cambios en estructura orgánica

21 Distribución de actividades

36 Claridad de responsabilidades

44 Disponibilidad de herramientas / equipos / recursos

8 Difusión de información necesaria

18 Libertad de expresión

29 Comunicación ascendente

32 Conocimiento de logros

49 Comunicación informal 
Hipótesis: Con base en los argumentos de Cáceres (2010), que describe que tanto la religión cristiana-Católica como la religión cristiana-Evangélica, permiten una visión global de la vida con sensibilidad humana a la de una comunidad de creyentes o más extensible a una sociedad en pleno, donde lo valores y la preocupación al prójimo es base de sus filosofía o idealismo religioso. Se puede inferir que los empleados que trabajan en universidades con enfoque religiosos deben sentirse más satisfechos, contentos y leales a su universidad, en comparación a los que trabajan en universidades laicas. Y si el clima laboral son las percepciones compartidas que tienen los miembros de una organización (empleados, directivos, personal de apoyo y socios) y su repercusión o influencia ya sea positiva o negativa en la satisfacción laboral, el ambiente de trabajo y por ende en la productividad de la empresa, este clima laboral se forma con base en esas percepciones y comportamientos de los integrantes de una organización. Bajo esta perspectiva, se han planteado las siguientes, y se describen las relaciones de las variables en el modelo, ver Tabla 4, para las hipótesis propuestas:

$\mathrm{H}_{1}$ : La Satisfacción laboral (motivación) de los empleados en las universidades privadas con enfoque religioso influye en un mejor 0 un ambiente positivo en el clima laboral en comparación con las universidades con enfoque laico.

$\mathrm{H}_{2}$ : La Identidad laboral (relaciones) de los empleados en las universidades privadas con enfoque religioso influye en un mejor 0 un ambiente positivo en el clima laboral en comparación con las universidades con enfoque laico.

Tabla 4.

Modelo hipotético con variables.

\begin{tabular}{cl|ccc}
\multicolumn{2}{c}{ Variables } & $\begin{array}{c}\text { Factor } \\
\text { Detonante }\end{array}$ & $\begin{array}{c}\text { Impacto en el } \\
\text { Ambiente laboral }\end{array}$ & Resultado \\
\hline 1. & $\begin{array}{l}\text { Remunera } \\
\text { ción }\end{array}$ & Motivación & Satisfacción & \\
2. & $\begin{array}{l}\text { Autonomía } \\
\text { 3. }\end{array}$ & Formación \\
4. & Planeación & & & Clima \\
1. & Conflicto \\
2. & Líder \\
3. & Comunicac & Relaciones & Identidad & Clima laboral \\
4. & ión & laboral & \\
4. & & & \\
\hline
\end{tabular}

Fuente: Elaboración propia.
Asimismo, para la presente investigación se realizó la prueba ANOVA para la comparación de medias de tres grupos clasificados como UM (universidad Metodista), UJ (universidad Jesuita) y UL (universidad Laica). Bajo un diseño ex post facto ${ }^{3}$ retrospectivo ${ }^{4}$ (León \& Montero, 2003), que permitió analizar las medias de la variable factor a la motivación-satisfacción laboral ${ }^{5}$, como se observa en la Tabla 5, procurando la mayor representatividad de la población de cada grupo (Altman \& Bland, 1996). Para lo cual se ha definido como variables dependiente $e$ independiente las siguientes:

- La variable dependiente para la presente investigación es el clima organizacional, definida como las percepciones compartidas que tienen los miembros de una organización (empleados, directivos, personal de apoyo y socios) y su repercusión o influencia ya sea positiva o negativa en la satisfacción laboral, el ambiente de trabajo y por ende en la productividad de la empresa, este clima laboral se forma con base en esas percepciones y comportamientos de los integrantes de una organización, y en este caso desde la perspectiva religiosa.

- Las variables independientes son la identidad laboral (relaciones) y la satisfacción laboral (motivaciones).

- La motivación es entendida como un estado emocional que se genera en una persona a consecuencia de la influencia que ejercen determinados motivos en su comportamiento, que determina el grado en que el empleado siente satisfacción en el puesto y las actividades que realiza en la organización (Chaparro, 2006 y García \& Ibarra, 2010).

- La variable de satisfacción laboral es un factor que determina el grado de bienestar que un sujeto experimenta en su área de trabajo (Locke, 1991). Y se puede definir como un conjunto de propiedades

\footnotetext{
${ }^{3}$ El término ex post facto significa después de hecho. En este tipo de diseño "el investigador se plantea la validación de las hipótesis cuando el fenómeno ya ha sucedido (León \& Montero, 2003).

${ }^{4}$ Donde la Variable Dependiente VD y la Variable Independiente VI ya han ocurrido (Incapacidad para garantizar la antecesión de la VI respecto a la VD) (León \& Montero, 2003).

5 En este caso, solo se seleccionó la variable independiente de Satisfacción laboral y se dejó para un posterior análisis (full communication), el análisis de la otra variable independiente Identidad laboral, a través de ecuaciones estructuradas (Rubiano \& Aponte, 2014).
} 
ISSN: 1794-9920 - ISSN Electrónico: 2500-9338

Enero - Julio de 2018

Volumen 18 Número 1, Año 2018 Págs. 53 - 75

medibles del ambiente de trabajo (el salario, las condiciones de trabajo, la estimulación, los métodos de dirección, las relaciones interpersonales, las posibilidades de superación y el desarrollo

profesional) que son percibidos por las personas, influenciando su ambiente, su motivación y su comportamiento (Ahmed, Khan, \& Butt, 2012).

Tabla 5.

Modelo de Variables.

\begin{tabular}{|c|c|c|c|}
\hline \multicolumn{2}{|r|}{ Ítems } & $\begin{array}{c}\text { Variables } \\
\text { Independientes }\end{array}$ & Variable Dependiente \\
\hline & Variables & $\begin{array}{c}\text { Impacto en el Ambiente } \\
\text { laboral }\end{array}$ & Resultado \\
\hline $\begin{array}{l}1 . \\
2 . \\
3 . \\
4 . \\
5 .\end{array}$ & $\begin{array}{l}\text { Remuneración } \\
\text { Autonomía } \\
\text { Formación } \\
\text { Planeación } \\
\text { Motivación }\end{array}$ & Satisfacción laboral & \\
\hline $\begin{array}{l}1 . \\
2 . \\
3 . \\
4 . \\
5 .\end{array}$ & $\begin{array}{l}\text { Conflicto } \\
\text { Lider } \\
\text { Comunicación } \\
\text { Compromiso } \\
\text { Relaciones }\end{array}$ & Identidad laboral & $\begin{array}{l}\text { Clima organizacional } \\
\text { (Clima laboral) }\end{array}$ \\
\hline
\end{tabular}

Con base en la operacionalización de variables, se ha determinado las siguientes hipótesis:

- $\quad$ Las medias de los grupos $\mu_{1}$ (UM) $\mu_{2}$ (UJ) y $\mu_{3}$ (UL) son iguales y por tanto las diferencias encontradas pueden explicarse por el azar. Es decir, no hay diferencias entre el grado de satisfacción laboral ni influencia en este por la religión que profesan: Hipótesis nula $\left(\mathrm{H}_{0}\right): \mu_{1}=$ $\mu_{2}=\mu_{3}$

- $\quad$ Las medias de los grupos $\mu_{1}$ (UM) $\mu_{2}$ (UJ) y $\mu_{3}$ (UL) no son iguales, 0 al menos uno de los grupos tiene una media distinta del resto de grupos. Es decir, si hay diferencias entre la satisfacción laboral y la influencia en este por la religión que profesan: Hipótesis alternativa $\left(H_{1}\right): \mu_{1} \neq \mu_{2} \neq \mu_{3}$.

\section{RESULTADOS Y DISCUSIÓN:}

Antes de aplicar la encuesta, se realizó la validación del instrumento (Cuestionario Versión A) con seis expertos. Los cuales analizaron y aportaron mejoras a cada variable 0 ítem. Los cambios recomendados fueron pocos y estuvieron relacionados con la homogenización en el uso de escalas (escala lineal de Likert, donde 1=Totalmente en desacuerdo y $5=$ Totalmente de acuerdo), teniendo la versión del Cuestionario B. Una vez ajustado el instrumento Versión B, para la fiabilidad de los 10 elementos del Modelo, se realizó una prueba piloto con 15 sujetos, quienes eran empleados de universidades objeto de estudio. $Y$ como resultado, no hubo cambios significativos (sólo en la redacción del ítem 10 y 39, los cuales fueron ajustados), ni cambios en el rediseño del instrumento y se obtuvo el Cuestionario Versión C. Cabe señalar que los sujetos que integraron la prueba piloto, para la etapa de aplicación de la muestra, ya no fueron contemplados. 
Una vez aplicado el instrumento Cuestionario Versión C en la etapa concluyente, a los 175 sujetos seleccionados por conveniencia, de tres universidades: dos con enfoque religioso y una sin enfoque religioso o laica (EvangélicaProtestante -EP, Católica-Jesuita -CJ y Laica Empresarial LE). Se calculó la consistencia interna basado en el Alfa de Cronbach, que permitió estimar la fiabilidad del instrumento. El cual fue de 0.970 para los 10 grupos de constructos, promedio de las 3 universidades. Para el instrumento de la universidad EP la fiabilidad fue .838, en la universidad -CJ fue de .950 y para la universidad LE fue de .934, todas en general se consideran adecuadas (Nunnally, 1978).

La muestra estuvo compuesta de la siguiente forma: Para el caso de la Universidad Jesuita se entrevistaron a 55 sujetos, para la Universidad Metodista a 61 sujetos y para la Universidad Laica-Empresarial a 59 sujetos en la etapa concluyente. En la Tabla 6, se puede observar el perfil de los sujetos entrevistados por universidad.

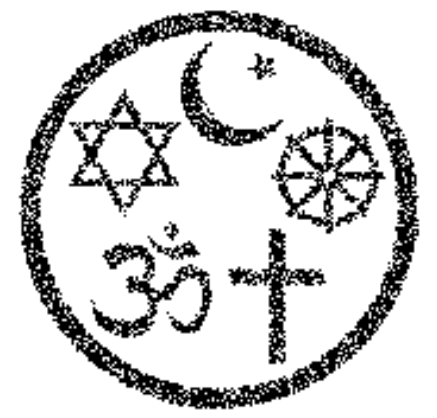

Tabla 6.

Perfil de los sujetos: Muestra.

\begin{tabular}{|c|c|c|c|c|}
\hline Universidad & $\begin{array}{l}\text { Total de } \\
\text { sujetos }\end{array}$ & Función & Religión & Género \\
\hline $\begin{array}{c}\text { Protestante } \\
\text { Metodista }\end{array}$ & 55 & $\begin{array}{c}\text { Directivo, Coord. Acad., Coord. } \\
\text { Admvo., Docente TC, Administrativo y } \\
\text { Empleado. }\end{array}$ & $\begin{array}{l}\text { Católica } 79 \% \\
\text { Evangélica } 21 \% \\
\text { Otro } 0 \%\end{array}$ & $\begin{array}{c}\text { Hombre } 48 \% \\
\text { Mujer } 52 \%\end{array}$ \\
\hline $\begin{array}{l}\text { Católica } \\
\text { Jesuita }\end{array}$ & 61 & $\begin{array}{l}\text { Directivo, Coord. Acad., Coord. } \\
\text { Admvo., Docente TC, Administrativo y } \\
\text { Empleado. }\end{array}$ & $\begin{array}{l}\text { Católica } 99 \% \\
\text { Evangélica } 1 \% \\
\text { Otro }\end{array}$ & $\begin{array}{c}\text { Hombre } 60 \% \\
\text { Mujer } 40 \%\end{array}$ \\
\hline $\begin{array}{c}\text { Laica } \\
\text { Empresarial }\end{array}$ & 59 & $\begin{array}{c}\text { Directivo, Coord. Acad., Coord. } \\
\text { Admvo., Docente TC, Administrativo y } \\
\text { Empleado. }\end{array}$ & $\begin{array}{l}\text { Católica } 71 \% \\
\text { Evangélica } 24 \% \\
\text { Otro } 5 \%\end{array}$ & $\begin{array}{c}\text { Hombre } 49 \% \\
\text { Mujer } 51 \%\end{array}$ \\
\hline
\end{tabular}

Fuente: Elaboración propia con SPSS 24. 
ISSN: 1794-9920 - ISSN Electrónico: 2500-9338

Enero - Julio de 2018

Volumen 18 Número 1, Año 2018 Págs. 53 - 75 que tengas internamente. Retomando que los jefes, no son siempre los adecuados resaltando nuevamente las diferencias religiosas. Lo mismo sucede en la universidad laica, con un grado de 2.91, también los empleados de esta

Análisis Comparativo. Como se puede observar en la Tabla 7, se tiene que:

Tabla 7.

Comparación de Medias: Universidades Puebla.

\begin{tabular}{|c|c|c|c|}
\hline \multirow[t]{2}{*}{ Estadísticos descriptivos } & \multicolumn{3}{|l|}{ Media } \\
\hline & Metodista & Jesuita & Laica \\
\hline Remuneración & 1.91 & 3.60 & 3.29 \\
\hline Relaciones & 2.60 & 3.51 & 2.91 \\
\hline Conflicto & 2.82 & 3.38 & 2.87 \\
\hline Compromiso & 2.80 & 3.29 & 2.58 \\
\hline Motivación & 3.18 & 3.42 & 2.91 \\
\hline Autonomía & 3.40 & 3.69 & 3.60 \\
\hline 7. Formación & 3.67 & 3.38 & 3.11 \\
\hline 8. Líder & 3.00 & 3.60 & 3.69 \\
\hline 9. Planeación & 3.13 & 3.60 & 2.58 \\
\hline 10. Comunicación & 2.62 & 2.82 & 2.09 \\
\hline $\mathrm{N}$ válido (según lista) 175 & 175 & & \\
\hline
\end{tabular}

Fuente: Elaboración propia con SPSS 24.

1. Remuneración: El Grado de satisfacción en relación al pago y prestaciones que recibe el empleado a cambio de su trabajo es considerado precario y no están satisfechos los coordinadores, docentes de tiempo completo y administrativos. Con una media de 1.91, se puede apreciar que los empleados de la universidad metodista no reciben una remuneración justa y consideran que el esfuerzo que realiza diario en su centro de trabajo no tiene relación con las horas de trabajo. El máximo fue 3 , en una escala de 5 . La universidad laica tiene un grado de 3.29 , sus empleados se sienten indiferentes a la relación esfuerzo de su trabajo y la remuneración que reciben, en comparación de los empleados de la universidad jesuita quienes tienen un grado de satisfacción más al, de 3.60 , aunque sigue en la escala de 3 , donde no todos se sienten satisfechos con la remuneración recibida.

2. Relaciones personales: El Grado de respeto, apoyo y consideración entre los compañeros del Departamento/Trabajo, es de 2.6 (de una media máxima de 5.0), el cual tampoco es considerado adecuado ni eficiente para los empleados de la universidad metodista. Los empleados no consideran que exista apoyo entre compañeros de trabajo presentando desconfianza entre ellos -a decir por los entrevistados, por causas de la filosofía religiosa que presentan o profesan (católica, metodista-evangélica y hasta laica). Consideran que la igualdad de trato no existe y que las relaciones profesionales son con base al grupo de relación personal universidad no consideran que las relaciones entre compañeros sean eficientes. Caso contrario pasa con la universidad jesuita, con un grado de satisfacción de 3.51, los empleados consideran que las relaciones entre ellos son mejor que en las demás universidades. Si bien sigue en un grado de 3 (ni de acuerdo ni en desacuerdo), en comentarios de los entrevistados, suponen que se da mejor la relación con base en la afinidad en la religión y filosofía de la institución.

3. Conflicto: El Grado en que las diferencias personales pueden interferir en el buen desempeño de los empleados es de 2.81 para la universidad metodista y de 2.87 para la universidad laica. En este constructo se puede notar que los apoyos para la solución de problemas son relativamente indiferentes.

Es decir, los empleados consideran que no existe apoyo en la alta dirección para solucionar los conflictos entre compañeros, ya que el ambiente interno, se puede decir, que no radica en el grado de simpatía que se tenga en la filosofía de la institución o enfoque religioso de la universidad. Ya que como se observa una universidad es con corte religioso y la otra no. La universidad jesuita presenta un grado de 3.38 , pero tampoco es adecuado. 
5. Compromiso organizacional: El Grado en que los trabajadores se sienten comprometidos con la universidad, con sus metas y objetivos de manera que puedan brindar un servicio de calidad es bajo, es de 2.58 para la universidad laica, el más bajo en las 3.

Para la universidad metodista es de 2.80 , se puede observar que en estas universidades no existe un compromiso laboral de los empleados para con la empresa. Se sienten poco orgullosos de centro de trabajo, no recomiendan a la institución siendo que algunos empleados no inscriben a sus hijos en los eventos, 0 escuelas que son parte del consorcio educativo. Aunque presentan un alto compromiso en ofrecer un mejor servicio y desempeñar sus actividades con calidad. Aunque la universidad jesuita los empleados tienen un grado de compromiso hacia su universidad de 3.29 , tampoco es lo suficiente para decir que los empleados están totalmente comprometidos.

5. Motivación: El Grado en que el empleado siente satisfacción en el puesto y las actividades que realiza en la universidad laica es de 2.91, no existe motivación en ellos y para el caso de la universidad metodista el grado es de 3.1, es indiferente y también no adecuado, los empleados no se sienten motivados. Debido a que no reciben reconocimiento ni se sienten realizados en el trabajo. $\mathrm{Si}$ bien tienen interés por trabajar, en las actividades que realizan pero no existe una satisfacción como tal. Nuevamente la universidad jesuita obtiene un grado mayor, de 3.42, pero también demuestra que los empleados no están motivamos en la universidad.

6. Autonomía: El Grado en que el trabajador es capaz de tomar decisiones y es responsable de las actividades que realiza, para la universidad jesuita es de 3.69. Ya relativamente se obtiene un grado más alto, en comparación de los constructos anteriores. Los empleados se sienten con iniciativa, sentimiento de autoridad lo que puede representar autonomía laboral y libertad en toma de decisiones en la realización de sus actividades. Con 9 décimas menos, es decir con 3.60, los empleados de la universidad laica se sienten también con una relativa autonomía en la realización de sus funciones. Caso contrario pasa en la universidad metodista, con un grado de 3.40 .

7. Formación profesional: El Grado en el empleado se encuentra satisfecho con las actividades que el Departamento/área/universidad le brinda en beneficio de su crecimiento y desarrollo profesional, donde debe radicar la igualdad de oportunidades, el desarrollo profesional, la empleados de la jesuita consideran mejores oportunidades en el desarrollo laboral pero no en el desarrollo de capacitaciones. Detonando que perciben igualdad de oportunidades para todos los empleados. La universidad laica con un grado de 3.11, los empleados consideran que no existe como tal una formación profesional.

8. Liderazgo: El Grado en que los jefes apoyan, estimulan y dan participación a sus colaboradores. Contrariamente en comparación al constructo anterior, la universidad laica presenta un grado de 3.69 considerando, que los empleados perciben un liderazgo de sus jefes orientado al logro, que es participativo y que es un liderazgo apoyador. La universidad jesuita, también lo tiene, o lo percibe el empleado, ya que sus grado es de 3.60 , consideran que cuentan con un liderazgo directivo y que existencia de liderazgo de sus jefes. Caso contrario pasa en la universidad metodista, no consideran la existencia de un liderazgo en los jefes, el grado es de 3.00 .

9. Planeación: El Nivel de efectividad en el establecimiento de objetivos, distribución de actividades y responsabilidades, lo consideran casi adecuados $-\mathrm{y}$ es el más alto de las 3 universidades, para los para los empleados de la universidad jesuita. El nivel de efectividad de planeación es de 3.60 , los empleados consideran que las políticas de trabajo, la distribución de actividades, la claridad de responsabilidades, la disponibilidad de herramientas / equipos / recursos y a la comunicación es relativamente adecuada. Para los empleados dela universidad metodista y laica no lo es, ya que el nivel de efectividad es de 3.13 y 2.58 respectivamente.

10. Comunicación. El Nivel de efectividad en el flujo de información para la adecuada consecución de tareas. Para el caso de las 3 universidades, la metodista, la jesuita y la laica, no existe un nivel de efectividad en el flujo de información. Lo que representa limitantes en la consecución de actividades y el logro de resultados positivos. Para la universidad metodista no existe la liberta de expresión ni el reconocimiento y conocimiento de logros. Para la universidad jesuita no existe una comunicación ascendente y cuenta con mayor peso la comunicación informal. Y para la universidad laica no existe la difusión de la información. El nivel de efectividad 
en el flujo de información para la universidad metodista es de 2.62 , para la jesuita es de 2.82 y para la laica es de 2.09 .

Comprobación de Hipótesis: Con base en los resultados obtenidos en el análisis de correlaciones basado en el coeficiente de Pearson, como se puede observar en la Tabla 8 y Tabla 9, respecto a las hipótesis se tiene:

\section{$\mathrm{H}_{1}$ : Satisfacción Laboral}

- $\quad$ En la Correlación entre la Universidad Metodista con la Universidad Laica, se refuta la Hipótesis $\left(\mathrm{H}_{1}\right)$ La Satisfacción laboral (motivación) de los empleados en las universidades privadas con enfoque religioso influye en un mejor o un ambiente positivo en el clima laboral en comparación con las universidades con enfoque laico. Debido a que todas la correlación correspondientes a la Satisfacción Laboral son positivas bajas y hasta negativas (Johnson, 2003), excepto Motivación-Planeación con una $r=0.785$ y $p=0.138$ para la Universidad Metodista, como se observa en la Tabla 8.
- Con relación a la correlación entre la Universidad Jesuita con la Universidad Laica, se acepta la Hipótesis $\left(\mathrm{H}_{1}\right)$ La Satisfacción laboral (motivación) de los empleados en las universidades privadas con enfoque religioso influye en un mejor o un ambiente positivo en el clima laboral en comparación con las universidades con enfoque laico. Debido a que todas la correlación correspondientes a la Satisfacción Laboral son positivas altas (Johnson, 2003), excepto Motivación-Formación con una $r=0.890$ y $p=0.00$ para la Universidad Jesuita, como se observa en la Tabla 8.

Tabla 8.

Comprobación $\mathrm{H}_{1}$ : Satisfacción Laboral

\begin{tabular}{|c|c|c|c|c|}
\hline & & \multicolumn{2}{|c|}{ Motivación } & \multirow[b]{2}{*}{ Laica } \\
\hline & & Metodista & Jesuita & \\
\hline \multirow[t]{2}{*}{ Remuneración } & Correlación de Pearson & 0.122 & $0.789^{* *}$ & $0.554^{*}$ \\
\hline & Sig. (bilateral) & 0.065 & 0.001 & 0.023 \\
\hline \multirow{2}{*}{ Autonomía } & Correlación de Pearson & $-0.675^{\star *}$ & $0.856^{\star *}$ & $0.578^{*}$ \\
\hline & Sig. (bilateral) & 0.00 & 0.00 & 0.012 \\
\hline \multirow[b]{2}{*}{ Formación } & Correlación de Pearson & $0.455^{\star *}$ & $0.890^{\star *}$ & $0.892^{* *}$ \\
\hline & Sig. (bilateral) & 0.001 & 0.00 & 0.00 \\
\hline \multirow{3}{*}{ Planeación } & Correlación de Pearson & 0.785 & $0.764^{*}$ & $0.689^{*}$ \\
\hline & Sig. (bilateral) & 0.138 & 0.05 & 0.05 \\
\hline & $\begin{array}{l}{ }^{* *} \text { La correlación es si } \\
\text { * La correlación es sig }\end{array}$ & $\begin{array}{l}\text { al nivel } 0,01 \\
\text { al nivel } 0,05\end{array}$ & $\begin{array}{l}\text { eral) } \\
\text { eral) }\end{array}$ & \\
\hline
\end{tabular}

Fuente: Elaboración propia con SPSS 24. 


\section{$\mathrm{H}_{2}$ : Identidad Laboral}

- En la Correlación entre la Universidad Metodista con la Universidad Laica, se refuta la Hipótesis $\left(\mathrm{H}_{2}\right)$ La Identidad laboral (relaciones) de los empleados en las universidades privadas con enfoque religioso influye en un mejor o un ambiente positivo en el clima laboral en comparación con las universidades con enfoque laico. Debido a que todas la correlación correspondientes a la Identidad Laboral son positivas bajas y hasta negativas (Johnson, 2003), como se observa en la Tabla 8.
- Con relación a la correlación entre la Universidad Jesuita con la Universidad Laica, no existen elementos contundentes para aceptar o refutar la Hipótesis $\left(\mathrm{H}_{2}\right)$ La Identidad laboral (relaciones) de los empleados en las universidades privadas con enfoque religioso influye en un mejor 0 un ambiente positivo en el clima laboral en comparación con las universidades con enfoque laico. Debido a que 2 de 4 variables son altas y positivas respectivamente (Johnson, 2003). Es decir, en las correlaciones Relación-Conflicto y Relación-Liderazgo, presenta una mejor relación positiva alta la universidad Laica. $Y$ en las correlaciones Relación-Comunicación y RelaciónCompromiso, presenta una mejor relación positiva alta la Universidad Jesuita, como se observa en la Tabla 9.

Tabla 9.

Comprobación $\mathrm{H}_{2}$ : Identidad Laboral.

\begin{tabular}{|c|c|c|c|c|}
\hline & & \multicolumn{2}{|c|}{ Relaciones } & \multirow[b]{2}{*}{ Laica } \\
\hline & & Metodista & Jesuita & \\
\hline Conflicto & $\begin{array}{l}\text { Correlación de Pearson } \\
\text { Sig. (bilateral) }\end{array}$ & $\begin{array}{l}-0.563^{* *} \\
0.00\end{array}$ & $\begin{array}{l}0.214 \\
0.234\end{array}$ & $\begin{array}{l}0.901^{\star \star} \\
0.00\end{array}$ \\
\hline Líder & $\begin{array}{l}\text { Correlación de Pearson } \\
\text { Sig. (bilateral) }\end{array}$ & $\begin{array}{l}-0.453^{* *} \\
0.00\end{array}$ & $\begin{array}{l}0.874^{*} \\
0.02\end{array}$ & $\begin{array}{l}0.891^{\star \star} \\
0.01\end{array}$ \\
\hline \multirow[t]{2}{*}{ Comunicación } & $\begin{array}{l}\text { Correlación de Pearson } \\
\text { Sig. (bilateral) }\end{array}$ & $\begin{array}{l}0.112^{* *} \\
0.01\end{array}$ & $\begin{array}{l}0.893^{*} \\
0.05\end{array}$ & $\begin{array}{l}0.798^{\star \star} \\
0.00\end{array}$ \\
\hline & $\begin{array}{l}\text { Correlación de Pearson } \\
\text { Sig. (bilateral) }\end{array}$ & $\begin{array}{l}0.232^{*} \\
0.05\end{array}$ & $\begin{array}{l}0.899^{\star *} \\
0.00\end{array}$ & $\begin{array}{l}0.801 \\
0.21\end{array}$ \\
\hline Compromiso & $\begin{array}{l}\text { ** La correlación es signi } \\
\text { * La correlación es signif }\end{array}$ & $\begin{array}{l}\text { ivel 0,01 (bila } \\
\text { ivel 0,05 (bilat }\end{array}$ & & \\
\hline
\end{tabular}

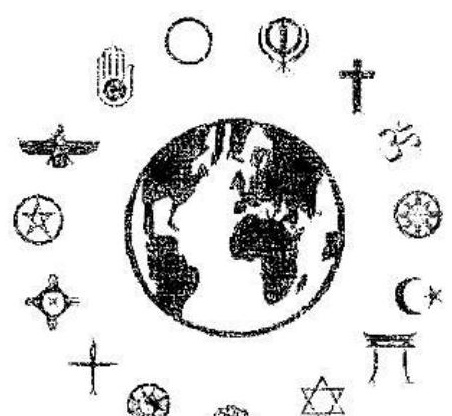


ISSN: 1794-9920 - ISSN Electrónico: 2500-9338

Enero - Julio de 2018

Volumen 18 Número 1, Año 2018 Págs. 53 - 75

Con base en los datos recabados y analizados con SPSS 24, para el análisis de ANOVA, se calcularon por grupo las Medias (M), la Desviación típica (DT), el Error estándar de la media (EEM) y el intervalo de confianza (IC). Como se puede observar en la Tabla 10 y 11, las medias comparadas: En la variable-factor Satisfacción Laboral (VSL), entre los grupos de enfoque religioso son diferentes. Obteniendo una media comparada de 2.21 para la UM (DT: 1.722 y EEM: 0.98), que se puede traducir a una baja

satisfacción laboral del empleado en este tipo de institución. Con una media de 3.89 para la UJ (DT: 1.123 y EEM: 0.67), se puede decir que casi todo el personal siente satisfacción laboral en este tipo de institución educativa y con una media de 4.23 para la UL (DT: 0.893 y EEM: 0.23 ), se puede afirmar que sin enfoque religioso por parte de la institución, los empleados se sienten satisfechos laboralmente en este tipo de universidad. Contrariamente a las dos primeras universidades (UM y UJ), que a pesar de contar con un enfoque religioso en sus estatutos y filosofía corporativa, sus empleados no están del todo satisfechos. calculan como número de casos (175) menos número de grupos (3) (Martínez, Sánchez-Villegas y Faulín, 2006). Por tanto la varianza intra-grupos (también llamada varianza residual) es 104.078/172 que es igual a 0.605 .

Una vez calculadas las varianzas inter e intra grupos, se calculó el cociente entre ambas y comprobar si el efecto observado (numerador) es tan grande como para no poder ser explicado por el error aleatorio (denominador). El cociente de ambas varianzas se denomina $\mathrm{F}$.

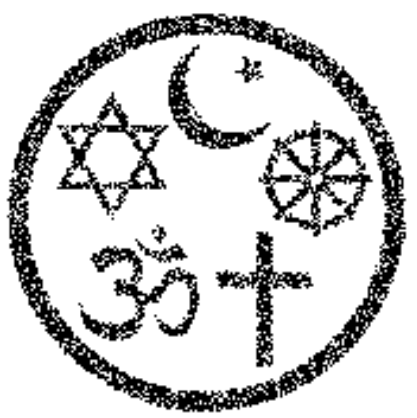

Tabla 10.

Descriptivos de Satisfacción Laboral (VSL) por grupos religioso.

\begin{tabular}{l|cccllll} 
& N & $\begin{array}{l}\text { Media } \\
\text { M }\end{array}$ & $\begin{array}{l}\text { Desviación Típica } \\
\text { DT }\end{array}$ & $\begin{array}{l}\text { Error } \\
\text { Estándar de la } \\
\text { Media } \\
\text { EEM }\end{array}$ & $\begin{array}{l}\text { Intervalo de Confianza } \\
95 \% \\
\text { IC }\end{array}$ & Mín. & Máx. \\
\hline $\begin{array}{l}\text { Satisfacción } \\
\begin{array}{l}\text { Enfoque UM: VSL } \\
\text { Satisfacción }\end{array}\end{array}$ & 55 & 2.21 & 1.722 & 0.98 & $(1.23-2.34)$ & 1.00 & 5.00 \\
$\begin{array}{l}\text { Enfoque UJ: VSL } \\
\text { Satisfacción }\end{array}$ & 61 & 3.89 & 1.123 & 0.67 & $(2.67-4.12)$ & 1.00 & 5.00 \\
$\begin{array}{l}\text { Enfoque UL: VSL } \\
\text { VSL Total }\end{array}$ & 59 & 4.23 & 0.893 & 0.23 & $(3.45-4.89)$ & 1.00 & 5.00 \\
\hline
\end{tabular}

Fuente: Elaboración propia con SPSS 24.

En la Tabla 11, se puede observar el resultado de la tabla ANOVA a través del programa SPSS 24. Se ha descompuesto la variabilidad total en dos filas: suma de cuadrados inter-grupos (entre los distintos grupos) y suma de cuadrados intra-grupos (dentro de cada grupo), divididas por sus correspondientes grados de libertad para obtener sus varianzas ANOVA (Stockburger, 1998). La suma de cuadrados inter-grupos mide la dispersión de la media de cada grupo respecto de la media total (10.255). En este caso son 3 grupos, los grados de libertad son 2 (se calculan como el número de grupos menos uno). Por tanto la varianza inter-grupos es de $10.255 / 3$ que es igual a 5.125. La suma de cuadrados intra-grupos mide la dispersión de cada observación respecto a la media de su grupo. Se tiene por tanto los grados de libertad y se
Dando como resultado $F=5.125 / 0.605 ; F=8.471$ (Tabla 3). Una vez que el valor de la distribución $F$ es conocido y está tabulado, se realizó el estadístico de contraste y superó cierto valor crítico, por lo que las diferencias son estadísticamente significativas. En concreto, el valor de F2, 172, 175 lleva una $p$ asociada de 0.004. Este valor de $p$ asociado a $\mathrm{F}$ corresponde a una distribución $\mathrm{F}$ de 2 grados de libertad en el numerador y 172 en el denominador. Entonces, con una $p^{6}$ asociada de 0.004 , se rechaza la

${ }^{6}$ El valor de referencia para aceptar o rechazar la hipótesis nula es el nivel de significación. Si el nivel de significación es mayor que 0.05 , se acepta la hipótesis nula de independencia entre las variables (no existen efectos diferenciales entre los tratamientos). Si el nivel de significación es menor que 0.05 se rechaza la hipótesis nula y se acepta la hipótesis alternativa, es decir, existe una relación de dependencia entre las 
hipótesis nula $\left(H_{0}\right): \mu_{1}=\mu_{2}=\mu_{3}$. $Y$ se concluye que si hay Emigdio Larios Gómez diferencias entre el grado de satisfacción laboral por la influencia en este de la religión que profesan. Debido a que existe diferencia en todas las medias de los grupos $\mu_{1}$ (UM) $\mu_{2}$ (UJ) y $\mu_{3}$ (UL). $O$ al menos en un grupo cuya media es distinta a la media del resto de los grupos. Es decir, el enfoque religioso en las universidades privadas en la

Ciudad de Puebla si influye en la satisfacción laboral de los empleados y por ende en el clima laboral de la organización. Esto querrá decir que la posición religiosa de las universidades privadas en la ciudad de Puebla en relación a la satisfacción laboral de los empleados son estadísticamente diferentes: Las medias de los grupos $\mu_{1}$ (UM) $\mu_{2}$ (UJ) y $\mu_{3}$ (UL) no son iguales, o al menos uno de los grupos tiene una media distinta del resto de grupos. Es decir, si hay diferencias entre la satisfacción laboral y la influencia en este por la religión que profesan: Hipótesis alternativa $\left(H_{1}\right): \mu_{1} \neq \mu_{2} \neq \mu_{3}$. satisfacción de las necesidades permanece en los niveles psicológicos y de seguridad. Aquí podemos observar que la influencia de la religión no es detonador para la construcción del tipo de clima laboral que presentan.
Tabla 11. Tabla ANOVA.

\section{CONCLUSIONES:}

Con base en la comparación descrita en el apartado anterior y en la literatura también descrita, sobre todo retomando Likert, (citado por Brunet, 1987). Se puede decir que:

1. La universidad con enfoque laico presenta un clima de tipo autoritario: Sistema I Autoritarismo explotador, debido a que la dirección no tiene confianza en sus empleados. La mayor parte de las decisiones y de los objetivos se toman en la cima de la organización y se distribuyen según una función puramente descendente. Los empleados tienen que trabajar dentro de una atmosfera de miedo, de castigos, de amenazas, ocasionalmente de recompensas, y la

variables, y según sea el caso se puede decir que los distintos niveles del factor sí influyen sobre los valores de la variable cuantitativa (Martínez, Sánchez-Villegas y Faulín, 2006).

2. La universidad con enfoque evangélico, el Clima es de tipo autoritario: Sistema II - Autoritarismo paternalista, la dirección tiene una confianza condescendiente en sus empleados, como la de un amo con su siervo. La mayor parte de las decisiones se toman en la cima, pero algunas se toman en los escalones inferiores. Las recompensas y algunas veces los castigos son los métodos utilizados por excelencia para motivar a los trabajadores. Bajo este tipo de clima, la dirección juega mucho con las necesidades sociales de sus empleados que tienen, sin embargo, los empleados tienen la impresión de trabajar dentro de un ambiente estable y estructurado. Los empleados perciben que el ascenso y el desarrollo de carrera dependen de la identificación con la doctrina religiosa de la institución. La 
ISSN: 1794-9920 - ISSN Electrónico: 2500-9338

Enero - Julio de 2018

Volumen 18 Número 1, Año 2018 Págs. 53 - 75

influencia de la religión Evangélica-Protestante, con sus denominaciones o ramificaciones, hace que los empleados no perciban igualdad, sobre todo los que presentan 0 profesan la religión católica, quienes son la mayoría de empleados que integran la nómina.

3. La universidad con enfoque católico es de tipo participativo: Sistema III -Consultivo, la dirección que evoluciona dentro de un clima participativo tiene confianza en sus empleados. La política y las decisiones de toman generalmente en la cima pero se permite a los subordinados que tomen decisiones más específicas en los niveles inferiores. La comunicación es de tipo descendente. Las recompensas, los castigos ocasionales y cualquier implicación se utilizan para motivar a los trabajadores; se trata también de satisfacer sus necesidades de prestigio y de estima. Los empleados de estas universidades presentan un ambiente bastante dinámico en el que la administración se da bajo la forma de objetivos por alcanzar.

La religión ligada a la educación ha sido motivo de debate en todo el mundo y desde tiempos de antaño. Desde permitir la educación religiosa en las escuelas públicas, pasando por el impedimento a la libertad de elegir, o bien la libertad de elección y hasta de quienes defienden la laicidad en pleno siglo XXI. Aunque no sea aceptado por muchos, entre educación y religión siempre ha habido una relación estrecha porque ¿de dónde vienen las explicaciones sobre el orden cósmico y el lugar de los seres humanos en la vida? Y muchas respuestas derivan de un mandato divino. Ahora bien, si bien es cierto que históricamente, la religión ha tratado siempre de imponer límites indebidos a la ciencia, a la universidad y a todo aquello relacionado con el ser humano, debido a errores por parte de autoridades religiosas. Aún con todo y los aspectos negativos, no se puede romper el romper las relaciones entre la universidad, la ciencia, la educación y las religiones.

Desde esta perspectiva, podemos concluir que el enfoque religioso en las universidades no mejora las situaciones laborales o satisfacciones de los empleados. Es decir, la religión lleva implícito conceptos como valores, moral y ética, que no definiremos estos conceptos porque no son el centro de la investigación, pero si se puede decir que una institución que se jacte de tener un enfoque religioso, ya sea católico, evangélico o hasta musulmán. Deberá poseer una coherencia de sus manifiestos religiosos en la vida laboral de sus empleados, impactando para bien y como ejemplo de las instituciones que no poseen un enfoque religioso en sus estatutos, normas o directrices. Más aún si se trata de la educación, como giro o directriz de producción en la organización, pública o privada. Los resultados de la presente investigación, nos hace reflexionar sobre si las universidades con enfoque religioso, en realidad practican sus idealismos filosóficoreligioso y los vierte en el quehacer diario de la formación de alumnos y en el trato de sus empleados, repercutiendo en la generación de un clima o ambiente de cordialidad, satisfacción y lealtad hacia la institución educativa.

Ante la actual situación, de competitividad comercial y de una sociedad carente de valores, es necesario encontrar una ventaja competitiva en las organizaciones que les permita sobresalir, no solo económicamente, sino socialmente frente a su mercado, a sus consumidores y competidores. La religión es y puede ser esa ventaja competitiva en un mercado educativo latente de formar profesionistas ejemplares, lideres sensibles y con visión humana. Pero si el ideal religioso no se plasma en el ambiente laboral, en los productores de esos líderes y profesionistas, de que sirve que la universidad posea un enfoque religioso si su personal no se encuentra satisfecho.

\section{REFERENCIAS:}

Ahmed, N., Khan, M., \& Butt, F. (2012). A Comparative Study of Organizational Climate and Job Satisfaction in Public, Private and Foreign Banks. Asian Social Science, 8(4), 259-267.

Alford, R.R. (1980) «Religión y Política», en Roland Robertson. Sociología de la Religión, México: FCE, 291-299.

Altman, D.G. and Bland, J.M. Statistics Notes: Comparing several groups using analysis of variance. Br Med J, 1996. 312: p. 1472-1473.

Anzola, M. O. (2003). Una mirada de la cultura corporativa. Editorial Universidad externado de Colombia. Colombia.

Banco Mundial. (2000). La Educación Superior en los Países en Desarrollo: peligros y promesas. Promoción Universitaria. Santiago de Chile.Brunet, (1987)

Blanco, F. (2003) Jóvenes del tercer milenio, México: Universidad de Colima

Brunet, L. (1987). El clima de trabajo en las organizaciones: Definición, Diagnóstico y Consecuencias. Editorial Trillas. México.

Brunet, L. (2004). El clima de trabajo en las organizaciones: Definición, Diagnóstico y Consecuencias. Editorial Trillas. México. 
Cáceres, T. (2010). Presencia del cristianismo en la cultura universitaria: una aproximación a la comprensión del fenómeno religioso, desde la orientación y el asesoramiento. Trabajo de Grado presentado ante la Dirección de Postgrado de la Facultad de Ciencias de la Educación de la Universidad de Carabobo: Venezuela.

Cárdenas, L., Arciniegas, Y., \& Barrera, M. (2011). Modelo de Intervención en Clima Organizacional. International Journal of Psychological Researc, 2(2), 121-127. Recuperado de http://dialnet.unirioja.es/descarga/ articulo/3119145.pdf

Casanova, F. (2003). Formación Profesional y Relaciones Laborales. Organización Internacional del Trabajo. Montevideo

Chaparro, L. (2006). Motivación laboral y clima organizacional en empresas de telecomunicaciones. (Factores diferenciadores entre las empresas públicas y privadas). INNOVAR. Revista de Ciencias Administrativas y Sociales, 16(28), 7-32.

Chiavenato, Adalberto. (2001) "Administración de Recursos Humanos". $5^{\text {a }}$ Edición. Colombia: Editorial McGraw Hill.

Cuadra, A., \& Veloso, C. (2007). Liderazgo, Clima y Satisfacción Laboral. Revista Universum, 2(22), 40-56

Davis, k. \& Newstrom, J. W. (2002). Comportamiento

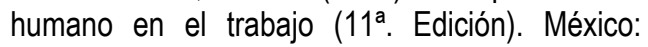
McGraw Hill Interamericana Editores, S.A.

De la Rosa, M. (Coord.) (1985) Religión y política en México, México: Siglo XXI.

Dessler, G. (1979). Organización y Administración. Editorial Prentice-Hall.

Dittes, J. E (1969) «Psychology of Religion», in G. Lindzey \& E. Aronson. Handbook of Social Psychology, Reading.

García e Ibarra (2010), Diagnóstico de Clima Organizacional Del Departamento De Educación De La Universidad De Guanajuato. http://www.eumed.net/librosgratis/2012a/1158/tipos_de_clima_organizacional _de_likert.html
Ibarra Manrique, L. Coordinador (2009). Procesos Educativos: miradas institucionales. Libro colectivo del cuerpo académico: Procesos Educativos. Guanajuato, Gto.

Johnson, Robert. (2003). Estadística Elemental, Ed. Math Learning, Ed. Tercera, México DF.

Kerlinger, F. (2002). Investigación del comportamiento. México, Mc Graw-Hill.

León, O. G. y Montero, I. (2003). Métodos de investigación en Psicología y Educación ( $3^{\mathrm{a}}$ ed.). Madrid: McGraw-Hill.

Likert, R. (1961). New patterns of management, New York, McGraw Hill.

Locke, E. P. (1991). "The motor sequence, the motivation hub, and the motivation core", Organisational Behaviour y Human Decision Processes, 50, 28899.

Luengo, E. (1993) La Religión y los jóvenes de México: ¿EI desgaste de una relación? México: UIA (Cuadernos de cultura y religión, 3).

Martínez González, M.A., Sánchez-Villegas, A., and Faulín Fajardo, F.J. Comparación de k medias (tre 0 más grupos). Bioestadística Amigable. $2^{\mathrm{a}}$ Edición. Ed: Díaz de Santos. 2006: p. 419-469.

Mass, Addison Wesley; Edelberg, G. S. (2006). La espiritualidad y la religión en el trabajo. Revista de la Escuela de Administración de Negocios, 58, 135-140.

Méndez Álvarez, C. (2006). Clima organizacional en Colombia, Bogotá. El IMCOC: Un método de análisis para su intervención Centro Editorial Universidad del Rosario.

Muñoz-Sedano, Antonio, (1992), Modelos de organización escolar, Madrid, Ed. Cincel.

Nunnally, J. C. (1978). Psychometric theory (2nd ed.). New York: McGraw-Hill.

Peña, M., Díaz, M., \& Carrillo, A. (2013). Relación de Factores en la Satisfacción Laboral de los Trabajadores de una Pequeña Empresa de la Industria Metal - Mecánica. Revista Internacional de Administración \& Finanzas, 6(3), 115-128 
Rahimic, Z., (2013). Influence of Organizational Climate on Job Satisfaction in Bosnia and Herzegovina Companies. International Business Research, 6(3), 129-139.

Rama, C. (2012). La nueva fase de la universidad privada en américa latina. Serie: Textos universitarios / Investigación. Fondo Editorial de la Universidad Inca Garcilaso de la Vega: Lima, Perú.

Rodríguez, D. (1999). Diagnóstico Organizacional. Editorial Alfaomega. México. D.F.

Rokeach, M. (1973). «The Consumer's Changing Image» \& "Paradoxes of Religious Belief», in Elliot Aronson, et al. Social Psychology, New York:D. Van Nostrand Company, pp. 33-39 y 169-172.

Rokeach, M. (Ed.) (1960). The Open and Closed Mind, New York: Basic Books.

Rubiano, M. G., \& Aponte, C. F. (2014). Motivación y satisfacción laboral como facilitadores del cambio organizacional: una explicación desde las ecuaciones estructurales. Psicogente, 17(31), 120-142.

Schein, E. (1985). Organizacional culture and leadership, San Francisco, Josey-Bass, 1985, pág 9.

Seisdedos, N. (1996). "El clima laboral y su medida", Revista "Psicología del Trabajo y de las Organizaciones" (Núm. 2).

Silva, M. (1996). El Clima en las Organizaciones. Editorial EUB. Barcelona.

Starbuc k, E.D. (1899). The Psychology of Religión, New York: Scribner.

Stockburger, D.W. ANOVA. Why Multiple Comparisons Using t-tests is NOT the Analysis of Choice. http://davidmlane.com/hyperstat/intro ANOVA.ht ml. 1998.

Topete, C., \& Cerecedo, M. T. (2001). El ejercicio del poder como transformación y conflicto en los centros educativos. In Memoria VI Congreso Nacional de Investigación Educativa (pp. 6-10).

Velasco. (2004). La experiencia mística. Estudio interdisciplinario. Editorial trotta. Madrid, España.
Zamora, N. (2005). El Liderazgo en el Clima Organizacional y sus Repercusiones en la Creación de Valor (Tesis de maestría). Instituto Politécnico Nacional, México. Recuperado de http://hdl.handle.net/123456789/1135 